Brit. F. vener. Dis. (1972) 48, 342

\title{
Effect of gentamicin sulphate on avirulent and virulent Treponema pallidum
}

\author{
N. N. IZZAT, E. B. SMITH*, AND J. M. KNOX \\ From the Department of Dermatology and Syphilology, Baylor College of Medicine, Houston, Texas 77025, \\ and the Syphilis Research Laboratory, Veterans Administration Hospital, Houston, Texas 77031, U.S.A.
}

The bactericidal activity of the aminoglycoside gentamicin has been demonstrated against a broad spectrum of bacteria (Jackson and Finland, 1969). This spectrum included Neisseria gonorrhoeae (Waitz and Weinstein, 1969); however, before gentamicin is used for the treatment of gonorrhoea, its effect on Treponema pallidum should be investigated to determine whether it can delay or mask the development of syphilis, a much more serious venereal disease. This report describes the effect of varying concentrations of gentamicin sulphatef on avirulent $T$. pallidum in culture medium, as well as on virulent $T$. pallidum in infected rabbits.

\section{Material and methods}

Nichols pathogenic and non-pathogenic strains of $T$. pallidum were used in this investigation. The pathogenic strain was maintained in the testes of normal rabbits and serially transferred every 11 days. The non-pathogenic strain was maintained in an enriched Spirolate medium recently developed by this laboratory.

Throughout this study, New Zealand male rabbits were used which initially had non-reactive serological tests (VDRL, FTA-ABS) and no evidence of infection with Treponema cuniculi.

\section{EFFECT OF GENTAMICIN ON AVIRULENT T.PALLIDUM}

Gentamicin sulphate was added to the medium in each of twelve flasks: four contained $400 \mu \mathrm{g}$. $/ \mathrm{ml}$., four contained $100 \mu \mathrm{g} . / \mathrm{ml}$., and another four contained 12.5 $\mu \mathrm{g} . \mathrm{ml}$. Four control flasks were prepared without the antibiotic. The sixteen flasks, each containing $200 \mathrm{ml}$. medium, were inoculated with approximately $9 \times 10^{8}$ avirulent Nichols strain of $T$. pallidum and incubated at $35^{\circ} \mathrm{C}$. The growth of $T$. pallidum was quantitated with darkfield counts and turbidimetric measurements as previously reported from this laboratory (Izzat, Knox, and Wende, 1971).

Received for publication February 2, 1972

*University of New Mexico Medical School, Department of Medicine, Albuquerque, New Mexico

tGentamicin sulphate was supplied as Garamycin by the Schering Corporation, Bloomfield, New Jersey.

\section{EFFECT OF GENTAMICIN ON VIRULENT T.PALLIDUM}

To evaluate the effect of gentamicin on primary syphilis lesions, a suspension containing 100 treponemes per 0.1 $\mathrm{ml}$. was prepared. $0 \cdot 1 \mathrm{ml}$. of this suspension was inoculated intradermally into four sites on the back of each of sixteen rabbits. When the resulting lesions reached a diameter of $9 \mathrm{~mm}$., darkfield examinations were performed to establish the diagnosis of primary syphilis. Ten rabbits, each with four primary lesions, were treated with gentamicin sulphate, $8 \mathrm{mg}$. $/ \mathrm{kg}$., given as a single intramuscular injection. This dosage is recommended by the manufacturer for the treatment of gonorrhoea in humans. Two rabbits were given procaine penicillin G, $120 \mathrm{mg} . / \mathrm{kg}$., in a single injection, and four additional rabbits were left untreated. Further darkfield examinations were performed on one of the lesions of each animal at $0,6,12,24,72$, and $120 \mathrm{hrs}$ after treatment.

A second experiment was performed to determine the effect of gentamicin given during the incubation period of experimentally-produced syphilis in rabbits. Four groups of six rabbits each were inoculated intradermally at four sites on the back with 100 virulent treponemes (Nichols). On the day of inoculation, one group of six rabbits was treated with gentamicin, $8 \mathrm{mg} . / \mathrm{kg}$., intramuscularly, and 5 days after inoculation the six rabbits in the second group were treated with the same dose. Rabbits in Groups 3 and 4 were treated 10 and 15 days respectively after inoculation of the treponemes. A fifth group of four rabbits was left untreated. All animals were observed for the development of lesions. Darkfield examinations were then performed to confirm the presence of treponemes. Serological tests for syphilis (VDRL and FTA-ABS) were made before treatment and 28 days after treatment.

\section{Results}

The effect of gentamicin on the growth of $T$. pallidum in vitro is shown in Figs 1 and 2. Multiplication of treponemes incubated in medium containing 400, 100 , and $12.5 \mu \mathrm{g} . / \mathrm{ml}$. gentamicin was inhibited when compared to the multiplication of treponemes incubated in Spirolate growth medium without gentamicin. However, organisms continually exposed to the selected concentrations of gentamicin were not destroyed and remained motile. 


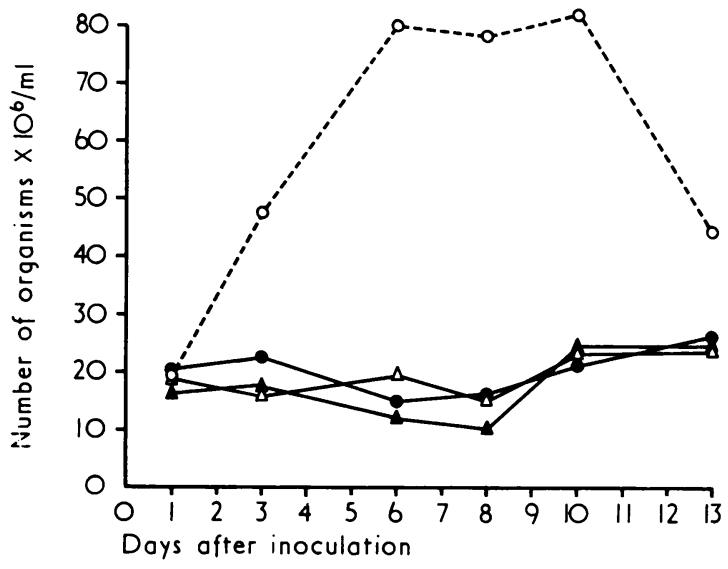

FIG. 1 Darkfield counts of avirulent Treponema pallidum (Nichols) in Spirolate growth mediumgentamicin mixtures over a 13-day period

The effect of gentamicin on darkfield positive lesions is shown in Table I. All four sites of each of sixteen rabbits inoculated with 100 organisms per site developed darkfield positive lesions. After the administration of gentamicin on Day 19, the chancres remained darkfield positive at $0,6,12$, and $120 \mathrm{hrs}$ after treatment, as did all the lesions of the four untreated control animals. The animals treated with penicillin became darkfield negative in $6 \mathrm{hrs}$ and remained so throughout the observation period. All lesions in those treated with gentamicin and in the control animals persisted until the animals were killed on Day 35. Before treatment with gentamicin, all the animals had positive FTA-ABS serological tests, and this test remained positive after treatment

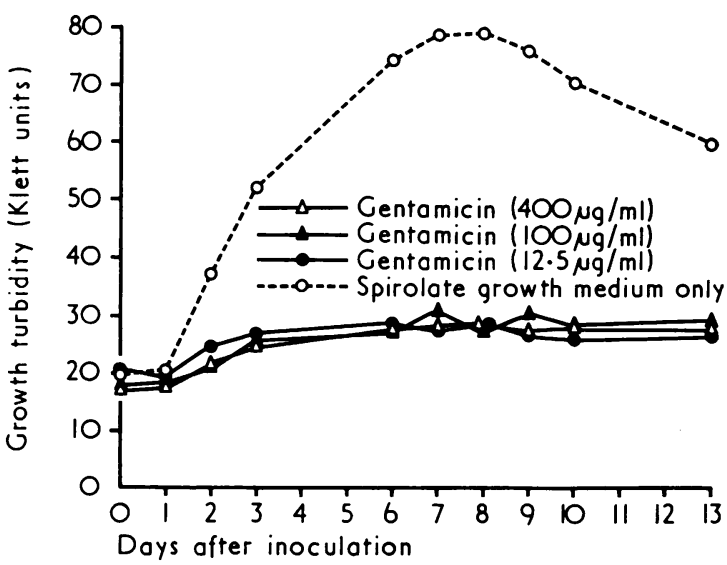

FIG. 2 Turbidimetric measurement of avirulent Treponema pallidum (Nichols) in Spirolate growth medium-gentamicin mixtures over a 13-day period

with gentamicin. The VDRL test results were not uniformly reactive before treatment but were positive by the 28 th day after treatment.

Gentamicin did not alter the course of incubating syphilis and all the animals developed darkfield positive lesions between 16 and 19 days after inoculation (Table II, overleaf).

By Day 28, all animals in all groups had developed positive VDRL and FTA-ABS tests.

\section{Discussion}

The aminoglycoside antibiotics streptomycin (Turner and Hollander, 1957), kanamycin, and dihydrostreptomycin have proved to be of no practical value

TABLE I Effect of gentamicin sulphate on rabbits with primary syphilis lesions

\begin{tabular}{|c|c|c|c|c|c|c|c|c|c|c|}
\hline \multirow{2}{*}{ Group ${ }^{a}$} & \multirow{2}{*}{$\begin{array}{l}\text { Positive } \\
\text { sites }^{\mathrm{b}}\end{array}$} & \multicolumn{3}{|c|}{ Before treatment } & \multicolumn{6}{|c|}{ After treatment } \\
\hline & & $\begin{array}{l}\text { Average } \\
\text { incubution } \\
\text { period } \\
\text { (days) }\end{array}$ & $\begin{array}{l}\begin{array}{l}\text { Per cent. } \\
\text { serological } \\
\text { changes }\end{array} \\
V D R L\end{array}$ & $F T A-A B S$ & 0 & 6 & 12 & 120 & $V D R L$ & $F T A-A B S$ \\
\hline $\begin{array}{l}\text { Gentamicin } \\
\text { treated } \\
(8 \mathrm{mg} . / \mathrm{kg})\end{array}$ & $40 / 10$ & 18 & 40 & 100 & 100 & 100 & 100 & 100 & 100 & 100 \\
\hline $\begin{array}{l}\text { Penicillin G } \\
\text { treated } \\
\text { control } \\
(120 \mathrm{mg} . / \mathrm{kg} .)\end{array}$ & $8 / 2$ & 17 & 100 & 100 & 100 & 0 & 0 & 0 & 100 & 100 \\
\hline $\begin{array}{l}\text { Untreated } \\
\text { control }\end{array}$ & $16 / 4$ & 17 & 25 & 100 & 100 & 100 & 100 & 100 & 100 & 100 \\
\hline
\end{tabular}

aAll rabbits were VDRL and FTA-ABS non-reactive at the start of the experiment.

besions are $9 \mathrm{~mm}$. or more in diameter and darkfield positive. Numerators show number of lesions; denominators show number of rabbits. 
TABLE II Effect of gentamicin sulphate on syphilis incubation period

\begin{tabular}{|c|c|c|c|c|c|}
\hline \multirow{2}{*}{$\begin{array}{l}\text { Group } \\
\text { no. }\end{array}$} & \multirow{2}{*}{$\begin{array}{l}\text { Gentamicin } \\
\text { treatment } \\
\text { (days after } \\
\text { inoculation) }\end{array}$} & \multirow{2}{*}{$\begin{array}{l}\text { Positive } \\
\text { sites }^{\mathrm{b}}\end{array}$} & \multirow{2}{*}{$\begin{array}{l}\text { Average } \\
\text { incubation } \\
\text { period } \\
\text { (days) }\end{array}$} & \multicolumn{2}{|c|}{$\begin{array}{l}\text { Per cent. serological changes } \\
(28 \text { days })\end{array}$} \\
\hline & & & & $V D R L$ & $F T A-A B S$ \\
\hline 1 & 0 & $24 / 6$ & 16 & 100 & 100 \\
\hline 2 & 5 & $24 / 6$ & 18 & 100 & 100 \\
\hline 3 & 10 & $24 / 6$ & 19 & 100 & 100 \\
\hline 4 & 15 & $24 / 6$ & 16 & 100 & 100 \\
\hline 5 & - & $16 / 4$ & 17 & 100 & 100 \\
\hline
\end{tabular}

All rabbits were VDRL and FTA-ABS non-reactive at the start of the experiment.

b Lesions are $9 \mathrm{~mm}$. or more in diameter and darkfield positive. Numerators show number of lesions; denominators show number of rabbits.

in the treatment of syphilis. Gentamicin sulphate, a new aminoglycoside antibiotic, might therefore be expected to have a similar lack of effect against the spirochaete. Nonetheless, this antibiotic has a broad range of activity against Gram-negative bacteria including Neisseria gonorrhoeae. Consequently, before extensive clinical studies are performed on patients with gonorrhoea, the effect of gentamycin on $T$. pallidum required further consideration. Our growth studies in vitro demonstrated that gentamicin, in continuous contact with avirulent $T$. pallidum, inhibits multiplication, but does not inhibit motility or cause the destruction of the intact treponemal cells. These results are in agreement with those of Holzmann, Tupath-Barniske, and Morsches (1969).

Our studies in vivo demonstrated that this bacteriostatic effect is of no clinical significance. Treatment of experimentally-produced primary syphilis in rabbits with gentamicin in the dosage levels which might be used for gonorrhoea had no effect on the clinical appearance of chancres and did not render established lesions darkfield negative. Furthermore, our studies have shown that gentamicin, $8 \mathrm{mg}$. $/ \mathrm{kg}$., administered at intervals during the 17-day incubation period of syphilis in rabbits, does not delay the appearance of chancres. Whether or not a higher dose would have any effect is not known, but the studies in vitro suggest otherwise.

\section{Summary}

Continuous exposure of avirulent $T$. pallidum (Nichols strain) to gentamicin sulphate in vitro at concentrations ranging from 12.5 to $400 \mu \mathrm{g} . / \mathrm{ml}$. prevented multiplication of the spirochaete, but did not affect motility. Gentamicin sulphate had no effect on incubating or established syphilis in experimentally-infected rabbits.

This study was supported in part by the Schering Corporation and in part by the John A. Hartford Foundation, Grant Number 3833. Technical assistance was provided by Miss Susan McCotter and Miss C. R. Wills.

\section{Summary}

Holzmann, H., Tupath-Barniske, H., and Morsches, B. (1969) Hautarzt, 20, 404

IzZAT, N. N., KNox, J. M., and Wende, R. D. (1971) Microbios (Camb.), 3, 247

JaCkson, G. G., and Finland, M. (1969) f. infect. Dis., 119,341

Turner, T. B., and Hollander, D. H. (1957) 'Biology of the Treponematoses,' p. 179. W.H.O., Geneva

Waitz, J. A., and Weinstein, M. J. (1969) f. infect. Dis., 119, 355

Effet du sulfate de gentamicine sur Treponema pallidum avirulent et virulent

SOMMAIRE

T. pallidum (souche Nichols) avirulent exposé d'une manière continue au sulfate de gentamicine in vitro à des concentrations allant de 12,5 à $400 \mu \mathrm{g}$. $/ \mathrm{ml}$. ne se multiplie pas mais sa mobilité n'est pas modifiée. Le sulfate de gentamicine est inefficace sur la syphilis, en incubation ou developpée, de lapins infectés expérimentalement. 